Cuestiones de filosofía

ISSN: 0123-5095

Vol. 1 - No. 17

Año 2015

pp. $258-274$

\title{
DELEUZE, EL PLIEGUE, EL RITORNELO Y LA RELACIÓN ARTE-TERRITORIO
}

\author{
Deleuze, the Ply, the Ritornello, and the \\ Art-Territory Relationship
}

\author{
Juan Camilo Roa-Corredor* \\ roac.juan@urosario.edu.co \\ Universidad del Rosario (Colombia)
}

Fecha de recepción: 11/11/2014

Fecha de evaluación: 24/02/2015

Fecha de aprobación: 15/09/2015

\section{Resumen}

"El arte es una territorialización expresiva"

Anne Sauvagnargues

El texto busca explorar la relación arte-territorio, examinando la posibilidad de hacerlo a partir de un estudio conjunto y simultáneo de la noción de pliegue y de ritornelo, conceptos que se convierten en los dos pilares conceptuales fundamentales sobre los cuales descansa la noción de geo-estética, sobre la que se pretende trabajar (giro espacial que acontece en la estética). Con la geo-estética no se busca eliminar el componente humano; en uno y otro caso, efectivamente, existe más arte en natura de lo que sabíamos, pero el ritornelo y el pliegue pueden ser empleados para graduar y modular esa relación entre seres vivos, arte y territorio. El pliegue tiene una realización matemática y topológica que, siendo radicalmente humana, muestra más claramente el carácter expresivo, no humano, de la naturaleza. El ritornelo, por su

* Universidad del Rosario.roac.juan@urosario.edu.co 
parte, es ese eterno retorno que da origen a la génesis del arte con la constitución de un territorio. Con el denominado "giro espacial" asistimos a un replanteamiento de los problemas espaciales tanto a nivel teórico como práctico, de ahí que sean posibles nuevos postulados que son sensibles a la diferencia y la especificidad. No basta que haya pintores, escultores o músicos para que haya arte, es menester una mirada y un pensamiento. La importancia que entra a ocupar el espacio permite condiciones de posibilidad que abren la puerta a la filosofía a cavilar la relación pensamientotierra-territorio.

Palabras clave: Territorio, Pliegue, Geo-estética, Ritornelo.

\begin{abstract}
This paper explores the Art-Territory Relationship, considering the possibility to do it from a joint and simultaneous study of the ply and ritornello notions, concepts, that become the fundamental basis on which reposes the geo-aesthetic concept, conceived as the spatial turn that takes place in the aesthetics. The geo-aesthetic doesn't look to eliminate the human component, but there's more art in nature than we thought. The ritornello and the fold can be used to regulate the relationship between human beings, art and territory. The ply has a mathematical and topological realization that, being human, shows clearly the expressive quality, not human, of nature. By its side, the ritornello is conceived as the eternal return that gives place to the art genesis, with the constitution of a territory. With the "spatial turn", we are attending to a rethinking of the spatial issues, both at theoretical and practical levels, hence it becomes possible new postulates sensitive to difference and specificity. It is not enough to have painters, sculptors or musicians to be art, for that a look and a though are necessary. The importance that the space comes to occupy, allows some possibility conditions that open the door to philosophy to ponder the relationship between thought-land-territory.
\end{abstract}

Key words: Territory, Ply, Geo-aesthetic, Ritornello.

La posibilidad de una geo-estética está latente no solo en la filosofía del propio Gilles Deleuze, sino en las condiciones de posibilidad que permitan percatar $u$ observar la estética de la naturaleza. Asistimos a un giro espacial en la estética, el cual hace viable hablar de una geo-estética, entendida, a la manera de Amalia Boyer, 
no propiamente como la búsqueda de los orígenes o la génesis del arte en la Tierra, sino más bien como la búsqueda del arte a partir de la diversidad de medios que terminan por condicionarlo. En últimas, se trata de describir un paisaje del devenir minoritario en territorio. Gilles Deleuze y Félix Guattari sostienen que la filosofía es una geo-filosofía, afirmación que tiene gruesas implicaciones:

En primer lugar, establece la primacía de la geografía como modelo del pensamiento sobre la historia. Segundo, suplanta la pregunta del origen (histórico y necesario) de la filosofía por la pregunta (geográfica y contingente) acerca del "medio" que condiciona su aparición. Tercero, pone el pensamiento en relación directa con la Tierra y el territorio, en vez de representarlo como la relación mediada entre sujeto (cognoscente) y objeto (conocido). Se produce así el desplazamiento de un paradigma epistemológico hacia un paradigma ético-estético (Boyer, 2009, p. 23).

En el presente escrito se buscará desarrollar una noción consistente de la geoestética, afirmando que ella sirve de referencia a la pregunta por el arte. Para ello, se expondrá que el pliegue es el concepto fundamental de la geo-estética, en tanto estética de la geología, de lo terrestre, y es que de la naturaleza misma puede surgir el arte. Los templos de Ellora; la ciudad de Petra, en Jordania; Capadocia, en Turquía; Matmata, en Túnez, o las Tumbas de la montaña, en Licia, son buenos ejemplos, pues en ellos se evidencia la posibilidad de extraer de las vetas de la naturaleza las formas que la arquitectura exige para erigir templos, un en-casa, aquella morada celosamente cuidada y construida, esa creación del territorio que permite un aislamiento del caos circundante y que se establece como creación artística en sí misma.

El texto trabajará sobre tres momentos (naturaleza, territorio y arte). En un primer momento se buscará argumentar que el pliegue está presente en la Tierra, en la geología; de manera que hay un germen artístico, si se quiere, presente en la misma naturaleza y sin que medie la acción del hombre. En un segundo momento se pretende señalar al ritornelo, creación artística territorializante, como la emergencia del arte, tal y como la conciben Deleuze y Guattari, en la que la creación del territorio asume un rol protagónico en el ejercicio creativo y artístico y en el que el pliegue se torna aún más evidente. Finalmente, se buscará argüir con ejemplos concretos que para la concepción de una geo-estética se han de necesitar unas condiciones de posibilidad que hagan viable la inteligibilidad y visibilidad de una estética de lo terrestre, y que ella goce de vigencia con expresiones artísticas de vanguardia, todo en virtud del giro espacial. 


\section{LA DIMENSIÓN TOPOLÓGICA DEL PLIEGUE}

En El pliegue. Leibnizy el barroco, Deleuze busca exponer la continua confección de pliegues como la función o rasgo operativo propio del barroco. Aun cuando el pliegue no sea exclusivo del barroco, en él los pliegues se curvan y recurvan, de manera que son llevados hasta el infinito. De ahí que Deleuze conciba el barroco como pliegue según pliegue, pliegue que va al infinito; así, dice, basta con observar la historia del pliegue infinito en todas las artes, aporte barroco que ha inspirado y está presente, por ejemplo, en las pinturas de Hantaï, Tintoretto o del Greco; en la novela de Proust o en la poesía de Mallarmé, o en el convento de Sainte Marie de La Tourette, de Le Corbusier. De lo anterior se desprende que la empresa del pliegue puede extenderse más allá del barroco, entendido como periodo artístico.

Es más, para Deleuze, el barroco no es tanto un periodo artístico, sino más bien un concepto que sugiere la posibilidad de llevar el pliegue hasta sus límites. Según Heinrich Wölfflin, mientras elespacio renacentista puede ser reducido a la superficie, el barroco, por su parte, no puede serlo, ya que en él el espacio se ve desarrollado en profundidad. Así se explica la insistencia del barroco en las curvas y demás formas oblicuas, que constituyen un evidente antagonismo con la cuadrícula renacentista, a lo cual hay que aunar el uso habitual de efectos luminosos que constantemente alternan con la disolución de los contornos con la penumbra. No en vano Deleuze destaca la tensión entre la fachada y el interior en la arquitectura barroca, fachada independiente e interior autónomo.

Una vez establecido que el pliegue puede presentarse allende las fronteras del barroco, o que el barroco, en tanto pliegue sobre pliegue, se puede rastrear en obras que no necesariamente estén comprendidas dentro de dicho periodo artístico, la definición del barroco pasa a un segundo plano; interesa más bien, para los propósitos aquí perseguidos, la potencia del pliegue en la topología.

Deleuze ve en la filosofía de Gottfried Wilhelm Leibniz el potencial de los pliegues artísticos que identifican el arte del periodo barroco. En efecto, Deleuze reconoce que el pliegue ha existido siempre en las artes, pero lo propio del barroco es el pliegue infinito, "pliegue según pliegue". Si la filosofía de Leibniz se puede considerar barroca por excelencia es porque en ella todo se pliega, se despliega y se repliega. Su tesis más célebre es aquella del alma como una "mónada", sin puertas ni ventanas, llena de pliegues oscuros, que extrae de un lóbrego fondo todos sus conocimientos y percepciones claras, que, por analogía, puede ser comparada con el interior de 
una capilla barroca, de mármol negro, en la que la luz pasa solamente por aberturas imperceptibles para el observador situado en el interior. En su Monadología, Leibniz concibe la idea de sustancia como una suerte de realidad autónoma e independiente, además de pluralista, ya que admite la existencia de una infinidad de sustancias múltiples que denomina mónadas, cuya naturaleza es inextensa, inmaterial, incomunicable e indivisible, "donde ya no hay partes, no hay extensión, ni figura, ni divisibilidad posible” (Leibniz, p. 21). Acá no interesan las cuestiones metafísicas en las que se sumergen Deleuze y Leibniz, también se dejará de lado la cuestión del barroco, la idea es enfocarse en el pliegue y la posibilidad de entender el espacio cósmico como medio amorfo que es atravesado por múltiples pliegues. En otras palabras, se trata de rastrear en la naturaleza amorfa y no intervenida, en la geología terrestre, la presencia de pliegues que permitan determinarlos como criterio estético característico de la geo-estética.

Como se dijo, el barroco no supone una esencia, sino más bien una función operativa: la continua confección de pliegues, en la que la distinción y distribución en dos pisos o niveles es lo barroco. El barroco curva y recurva los pliegues y los diferencia en dos direcciones: los repliegues de la materia, por uno, y los pliegues del alma, por otro. La naturaleza se muestra barroca en la medida en que no cesa de hacer pliegues, los curva y los recurva, pliegue sobre pliegue, de manera que los lleva al infinito. En el barroco, el pliegue es la articulación entre dos niveles, es el elemento que posibilita la correspondencia entre la fachada independiente y el interior autónomo, en la arquitectura barroca ${ }^{1}$. En palabras de Deleuze:

el piso de abajo se encarga de la fachada, y se alarga agujereándose, se curva según los repliegues determinados de una materia pesada, constituyendo una habitación infinita de recepción o de receptividad. El piso de arriba se cierra, puro interior sin exterior, interioridad cerrada en ingravidez, tapizada de pliegues espontáneos que ya sólo son los de un alma o de un espíritu. Por eso el mundo barroco, como ha mostrado WöIfflin, se organiza según dos vectores, el hundimiento abajo, el empuje hacia lo alto (1989, p. 43).

Ahora bien, retomando la concepción leibniziana, las mónadas son una suerte de sustancias activas. La energía es aquello que delimita a la mónada, es decir, es la

1 Para Wölfflin, "la última consecuencia fue entonces el plegamiento de toda la masa mural, que llevó a la fachada a encorvarse ligeramente sobre sí misma en los extremos, confiriéndole, por el contrario, en el centro, un movimiento vivo hacia delante, hacia el espectador" (p. 67). 
fuerza interior que anima a cada mónada, su espíritu, el elemento definitorio de las mismas. Las mónadas reflejan el universo, pues son sujetos de una infinidad de propiedades, y la esencia de cada sujeto, o mónada, está integrada, en últimas, por todos los predicados, incluyendo las relaciones con los demás sujetos o mónadas y con todo aquello que pueda acaecer. Para trazar el paralelo con Deleuze, es importante mencionar que las mónadas tienen una dimensión espiritual, pues son concebidas como almas racionales, espejo de la divinidad misma. Pero además del carácter metafísico que poseen, el concepto de mónada corresponde con la disposición barroca por excelencia, a saber: un cuarto sin puertas ni ventanas, pues "las mónadas no tienen ventanas por las cuales algo pueda entrar o salir" (Leibniz, 1974, p. 21). El barroco, en tanto pliegue según pliegue, pliegue que va al infinito, es ese cuarto sin puertas ni ventanas, en términos ideales, pues existen agujeros, al menos en lo que concierne a la arquitectura, es decir, existen aberturas a través de las cuales atraviesa la luz. Y es que al igual que la cámara barroca, el alma, en la filosofía de Leibniz, está llena de pliegues oscuros.

La Tierra se erige como mónada, la Tierra es materia oscura que, no obstante su opacidad, refleja la luz. Al igual que la mónada leibniziana y que la cámara oscura de la que habla Deleuze, la Tierra está plagada de pliegues, de agujeros ${ }^{2}$. No resulta extraño afirmar que la Tierra es mónada y que, en consecuencia, está llena de pliegues. Para Leibniz, el mundo, el universo, estaba constituido por mónadas organizadas armónicamente por Dios, de ahí que la Tierra sea mónada y que, tal como lo entiende Deleuze, no cese de hacer pliegues. La Tierra, en tanto materia, se pliega y repliega sobre sí misma. La Tierra está rebosada de pliegues oscuros, es interior sin exterior, exterior sin interior, sin puertas ni ventanas, así como "la mónada es la autonomía del interior, un interior sin exterior. Pero tiene como correlato... un exterior sin interior" (Deleuze, 1989, p. 42). El pliegue, por su parte, es la articulación de la Tierra con la Tierra misma, unión y diferencia, diferenciación diferenciante; la Tierra se distingue de ella misma, a la vez que se le puede concebir como una unidad, unidad que deviene en multiplicidad. Existe una autonomía de la Tierra con respecto al hombre, el arte no espera al hombre para emerger, pues con el giro espacial la Tierra tiene una lectura estética. El pliegue, por su parte, pasa a ser concebido como el mundo cósmico, el ojo de Dios leibniziano, en una visión topológica del

2 La cámara oscura toma importancia durante el periodo barroco y encuentra un uso sistemático en la pintura; sobre el uso de ella, Deleuze explica que "la cámara oscura sólo tiene una pequeña abertura arriba por la que pasa la luz, que por medio de dos espejos va a proyectar sobre la hoja los objetos que hay que dibujar pero que no se ven, debiendo estar inclinado el segundo espejo según la posición de la hoja" (Deleuze, 1989, p. 42). 
conjunto de la Tierra que resulta compatible con los trabajos desde la matemática realizados por Leibniz. Con la dimensión topológica del pliegue, es la Tierra misma la que viene a ser descrita, explorando una posibilidad artística en su seno. Pero para poder percatar la potencia estética de la Tierra, y del mundo cósmico, es menester que existan las condiciones de posibilidad que permitan la concepción de ese medio amorfo como potencia artística. Los ejemplos en este estadio carecen de relevancia; basta con observar un paisaje, un desierto, un terreno árido, una montaña, escenarios en los que el pliegue parece evidente; la cuestión está en comprender el pliegue como el elemento estético por excelencia de la topología.

\section{RITORNELO, CREACIÓN ARTÍSTICA TERRITORIALIZANTE}

La dinámica de la territorialidad resulta esencial en la obra de Deleuze. Además de ser recurrentes en otros de sus escritos, creación y territorialidad son los temas objeto de la meseta "del ritornelo" (Mil Mesetas); estos temas se abordan desde la etología, entendida como el estudio del carácter y los modos del comportamiento, no solo humano, sino animal. En el abordaje deleuziano se conjugan toda una serie de elementos por tener en cuenta en el ejercicio de creación (hábito, ritmo, medios y territorio), producto de las costumbres o del comportamiento animal o humano, que tienen la potencia de devenir en acto creador de naturaleza artística.

Pero, antes que nada, cabe preguntarse por el concepto de ritornelo mismo. El ritornelo es, sobre todo, una manera de conmensurar el tiempo; de ahí que no sea extraña la alusión de origen del ritornelo en la música. Pero el concepto resulta sui generis en Mil Mesetas, en el que se denota una clara influencia de la filosofía de Nietzsche, pues el ritornelo es concebido como una suerte de eterno retorno que nos permite volver sobre nosotros mismos. En efecto, en la filosofía nietzscheana el concepto del eterno retorno se configura como una intuición de que toda su vida estaba cifrada sobre sí mismo. De manera similar, el ritornelo de Deleuze y Guattari está constituido por el hábito y la posibilidad de que el acontecimiento pueda retornar a nuestra experiencia ${ }^{3}$. Con todo, no siempre que uno vuelve a "los lugares comunes" va a encontrar la misma experiencia, lo cual puede dar origen a experimentar distintos acontecimientos.

3 Sin embargo, al hablar del concepto de ritornelo de Deleuze y Guattari deben hacerse ciertas precisiones, pues la particular forma en que los autores hacen filosofía nos lleva a aceptar que la unidad de los autores se funde en la multiplicidad de sí mismos, de sus ideas, de manera que se hace imposible rastrear a Deleuze o Guattari, y es menester aceptar el devenir múltiple en el que se diluye la unicidad de estos. 
El arte, en la filosofía de Deleuze, es concebido como creación de un territorio, como un ejercicio territorializante. De ahí que aquel que territorialice termine, a su vez, inmerso en un ejercicio artístico, pues el arte es comprendido como una creación territorial. El ritornelo, como ese continuo estar volviendo, es la creación artística misma. Bien dice Sauvagnargues que "el territorio forma, pues, un centro, que es segundo y producido por retorno: en la constitución del territorio, los actos de salida son tan determinantes como los actos de apropiación, y el ritornelo comprende estas idas y venidas" (Sauvagnargues, 2006, p. 146). Y es que para Deleuze y Guattari, la construcción del territorio es el nacimiento del arte mismo, y esa creación de un territorio (ejercicio territorializante) se da en el tránsito entre medios (ritmo). ¿Pero cómo se da todo ese ejercicio territorializante? De entrada, el caos es asumido como una realidad, y es precisamente dentro de esa realidad caótica que surge el llamado a la necesidad de la creación, que solo puede tener cabida con el aislamiento (volver sobre sí mismo continuo), pues en el caos no se da la creación. La necesidad no surge por capricho, sino, valga la redundancia, por necesidad. De esa manera se crea el territorio, por necesidad de aislarse del caos circundante, y, con ello, se posibilita el ejercicio creativo. La creación territorializante surge del volver sobre los pasos, las huellas o los rastros resultantes del ritornelo. Así, el ritornelo es la creación del territorio, del aislamiento del caos, del lugar donde habitar, "el ritornelo cartografía los componentes expresivos (afectos y perceptos) que hacen posible recordar un "en-casa" en los medios caóticos no diferenciados" (Sauvagnargues, p. 143). La creación del territorio se logra mediante el tránsito entre los medios; los medios se encuentran dentro del caos; entre los medios se da un paso que crea el ritmo. El cambio de medio no es otra cosa, pues, que el ritmo.

Ahora bien, ¿cómo se da la creación del territorio a través del paso entre los medios? “Cómo asegura el ritornelo el tránsito del medio al territorio? Por un encadenamiento de signos que codifican materias y relaciones territoriales. Cada medio es un "bloque de espacio-tiempo" formado por repeticiones" (Sauvagnargues, p. 144). El tránsito entre medios tiende a crear una marca, una huella, un rastro, un distintivo, una apropiación, producto de la repetición. Es esa marca la que forma el territorio y la que, a su vez, aísla el caos, aun estando inserta en el caos. De manera similar ocurre en el arte; la práctica artística puede leerse como aquella generación de marcas o huellas que devienen en la creación del territorio, la transformación de las marcas que se configuran en el estilo, la firma misma, el distintivo del artista. Pero si el ritornelo expresa una multiplicidad de relaciones, por su parte la unicidad del volver sobre sí mismo, por la cual el acontecimiento retorna a la experiencia, deviene en multiplicidad de experiencias diversas, a la vez que distancia el caos, pura tensión 
de fuerzas, toda vez que la territorialización es la creación del espacio propio dentro del espacio caótico. Cabe indagar por qué consideran Deleuze y Guattari que el proceso de marcar un territorio o hacer un en-casa puede considerarse el punto de partida en que el arte emerge, sin que esto implique indagar por una génesis histórica de la geo-estética. Tal procedimiento (la marcación del territorio) deriva en la producción de trazos, marcas, huellas. En otras palabras, la operación consiste en que la materia deviene materia de expresión. "El ritornelo va hacia el agenciamiento territorial, se instala en él o sale de él. En un sentido general, se denomina ritornelo a todo conjunto de materias de expresión que traza un territorio, y que se desarrolla en motivos territoriales, en paisajes territoriales" (Deleuze y Guattari, 1994, p. 328).

Ahora bien, el rasgo deviene expresivo en el instante mismo en que alcanza una constancia temporal y espacial que lo transforma en una marca territorial, una firma en términos deleuzianos, y es que la acción de marcar un territorio es la operación misma del ritornelo, en la que se señala el devenir expresivo del ritmo, dando lugar a una suerte de movimiento de entradas y salidas constantes que se convierten en el sendero que lleva del hábito al hábitat territorial. En lo que respecta al hábito, este se constituye por la repetición, que agrupa una serie de actividades y medios; repetición que busca producir una diferencia (aislarse del caos). El ritmo, por su parte, se presenta por el paso o por la comunicación entre medios, de manera que se genera una coordinación de espacios distintos. Como se ha venido mencionando, en el momento en que se extrae un componente, sea del medio externo, sea del propio cuerpo (la carne), y este se convierte en un rasgo expresivo, se genera una marca. Con la reiterada generación de marcas se termina por esbozar un espacio en el que ritmos y medios se establecen con un dejo de permanencia, que es la misma reterritorialización.

Como se ha venido mencionando, la territorialización, en tanto fenómeno dinámico, es el mismo ritornelo de Deleuze y Guattari. Las constantes entradas y salidas del territorio, entendidas como descripciones propias de la etología, posibilitan la configuración del propio espacio que aísla el caos. Es en ese espacio propio en el que se genera la creación misma, creación que supone la generación previa del espacio propio que aísla el caos; de ahí que el arte, como creación, precise de ese ejercicio territorializante que está en constante transformación. Lo anterior, por cuanto el territorio no está dado, no preexiste, sino que lo precede la necesidad de aislamiento y el consecuente volver sobre sí por la vía del tránsito entre los medios que genera el territorio. La creación artística es constante, la generación del territorio es permanente, dinámica y circular, luego se presencia una continua territorialización, 
desterritorialización y reterritorialización ${ }^{4}$, en los que el arte se desprende de aquellos bloques de sensación que son tomados del territorio. Bien apunta Sauvagnargues que "como se ve, el arte no es la expresión de lo vital en general, sino de una territorialización que marca el umbral de la habitación en el seno del viviente" ( $\mathrm{p}$. 142), y que "territorializante, el ritornelo explora el modo de constitución espaciotemporal de un bloque de devenir" (p. 144).

En este aparte se ha buscado mostrar que con el ritornelo el espacio cósmico deviene territorio, que solo puede ser experimentado en el plano de inmanencia preciso de las expresiones, y es que es precisamente el territorio el que hace existencialmente posible la geo-estética. Las marcas se introducen en la tierra para producir la forma necesaria del en-casa que se busca delimitar. La Tierra es presupuesto para la formación del territorio. Ya se dijo que en las formaciones terrestres existe una suerte de germen artístico caracterizado por el pliegue, y sin que medie la intervención del hombre; pero es con el territorio que surge el arte para Deleuze. No se necesita del hombre para que el arte emerja, el arte va más allá de la carne, el arte es un ejercicio territorializante. Es por eso que, en la filosofía de Deleuze, el animal es un verdadero artista, la naturaleza deviene arte, la transformación del espacio cósmico en territorio es un ejercicio artístico que se experimenta en el plano de inmanencia de las expresiones. Cuando la Tierra deviene en territorio se puede afirmar la creación artística. Deleuze concibe el arte como un ejercicio territorializante, a la vez que ve al animal como un verdadero artista. Pero para percibir en el animal la potencia creadora, para poder concebir el arte en la naturaleza y, en consecuencia, para apreciar el arte como un ejercicio territorializante, es indispensable la exigencia de condiciones de posibilidad que permitan una concepción tal (la concepción de ese medio amorfo, naturaleza, como potencia artística), como se verá en el siguiente apartado.

\section{Pliegue y geo-estética}

El filósofo francés Jacques Rancière introduce el concepto de "la distribución de lo sensible", entendido como aquello que somos capaces de ver en cada tiempo. La distribución de lo sensible es objeto de una doble operación: lo que resulta común, o que se comparte, y lo exclusivo, de lo que se desprende quién puede compartir lo que es común a una comunidad, basado en lo que hace y el tiempo y espacio en el

4 La circularidad propia de la generación del territorio como creación artística se puede constatar con los procesos de territorialización, desterritorialización y reterritorialización. 
que desarrolla su actividad. En últimas, hablamos de formas de visibilidad, pues para que algo sea visible debe ser antes inteligible. No basta, entonces, que existan construcciones que convivan y provengan de la naturaleza, como las mencionadas en la introducción; se necesitan también las condiciones de posibilidad que permitan "ver" ese arte, arte que está sujeto a regímenes que determinan las posibilidades previas a la experiencia artística, a lo sensible. Las categorías kantianas vendrían a ser la distribución de lo sensible en lo que se refiere a la cuestión de la estética.

Rancière identifica tres regímenes, pero acá interesa el denominado "régimen estético de las artes", entendido como aquel sistema en el que asegura que se identifica al arte por un modo de ser sensible propio de los productos del arte, lo cual permite concebir la posibilidad de una geo-estética ${ }^{5}$. Y es que la estética no remite a una teoría de la sensibilidad, del gusto o del placer de los amantes del arte, remite más bien a un modo de ser específico, aquello que pertenece al arte, a un modo de ser de sus objetos.

En los planteamientos de Deleuze no existe una noción de la expresión que involucre necesariamente la existencia o presencia de un sujeto que se exprese a través de la obra de arte; precisamente, es la no exigencia del hombre la que permite visibilizar al animal como artista, pero también posibilita percibir el arte de lo terrestre, ya que es el territorio el que se expresa en tanto que resulta trazado, marcado, pues son las huellas territoriales la expresión del espacio que ha sido construido. La construcción del territorio deviene en expresión del territorio mismo; es por ello que para Deleuze la emergencia del arte no está en el cuerpo y la carne (sin desconocer su notable importancia en las artes), sino con el en-casa y el propio territorio. Con Rancière y su idea de lo visible, los pliegues de la materia y la visión de lo luminoso se hacen posibles; la Tierra que refleja la luz, pero que es opaca por excelencia, se hace inteligible como expresión estética. Así, pues, el medio amorfo lleno de pliegues se erige como potencia artística; basta con observar detenidamente la topología de lo terrestre, la naturaleza del espacio cósmico.

Deleuze y Guattari aseveraron que la filosofía es una geo-filosofía, lo cual da pie a pensar la posibilidad de una geo-estética, luego ¿qué debe entenderse por geo en la

5 El régimen estético de las artes es estético toda vez que la identificación del arte ya no se hace por medio de una distinción entre las maneras de hacer, sino por la distinción de un modo de ser sensible propio de los productos del arte. A partir de la estética se puede plantear la cuestión de las prácticas artísticas y, por qué no, de las prácticas geográficas como prácticas artísticas. 
geo-estética? Sauvagnargues sostiene que en Deleuze el arte es geo-grafía. El prefijo geo quiere denotar la posibilidad de concebir el arte como grafía, erigiendo una semiótica materialista en el arte, en la que los símbolos se comprenden como aquellas marcas, trazos, huellas de las que se ha hablado y que afirman un material de expresión, por lo que se manifiestan como prácticas geo-gráficas, toda vez que el territorio marcado solo puede ser experimentado en el plano de inmanencia preciso de las expresiones.

Ahora bien, en lo que concierne a la estética, esta se refiere a aquellas modificaciones e inflexiones realizadas por el ritornelo ${ }^{6}$. Dado que la territorialización es dinámica, las variaciones introducidas por el ritornelo son múltiples, dando lugar a una estética en la que el paisaje cumple un rol protagónico. Dicen Deleuze y Guattari que "los afectos son precisamente estos devenires no humanos del hombre como los perceptos (ciudad incluida), son los paisajes no humanos de la naturaleza" (1993, p. 170), de ahí que el arte, a través de la creación de perceptos, no reproduce aquello que es perceptible, sino que torna perceptible lo que era imperceptible (en términos de Rancière, hace visible e inteligible lo que antes no lo era). Es de esa manera que las fuerzas de la naturaleza devienen perceptibles. La naturaleza es un proceso en sí misma, la mímesis carece de sentido en este escenario, por eso se decía en el primer aparte que los ejemplos eran irrelevantes, ya que el espacio cósmico está plagado de pliegues con vocación estética. Y es que en términos de Rancière, en este momento el arte es identificado por un modo de ser sensible propio de sus productos, y no por las maneras de ser de ellos, por lo que el principio mimético pierde fuerza en relación con el factor territorializante; el arte ya no se limita a la imitación de una forma transportada a una materia, porque modelo y copia serían uno mismo, cosas producidas por las mismas fuerzas de la naturaleza, pues en ausencia del hombre no habría quién realizara copias del paisaje no humano. El percepto es paisaje sin hombre, paisaje no humano, es el devenir de la naturaleza en ausencia del hombre, la posibilidad del pliegue en el espacio cósmico.

Hasta el momento se han establecido dos postulados que brotan con la geo-estética; el primero se refiere a la génesis (no histórica y necesaria, sino geográfica y contingente) de una noción de territorio, para así poder determinar que el arte no necesita, $\mathrm{o}$ al menos no espera, al hombre para emerger ${ }^{7}$; el segundo concierne a la

6 El presente trabajo se centra en los signos visuales que delimitan un espacio de dimensiones variables, por lo que se dejará de lado el análisis del tiempo, que tampoco es pétreo, y el análisis sonoro (ritornelo y música).

7 No se trata de buscar el momento temporal en que el arte surge. 
elaboración de una noción de paisaje, en la que el arte es creación de perceptos, sin embargo, el paisaje no humano, la naturaleza en ausencia del hombre, no siempre permanece intacto. Si bien, en principio, la naturaleza puede leerse como paisaje en ausencia de la acción del hombre, no son pocas las veces en que se constatan intervenciones del hombre en el paisaje, justamente a través de la creación del territorio. La intervención del hombre es susceptible de ser concebida como arte en la geo-estética por las condiciones de inteligibilidad y visibilidad que permiten comprender la transformación física del mundo como una manifestación artística. La intervención efectuada en el paisaje es geografía física, que deviene en geografía estética (geo-estética), ya que la materia objeto de la transformación deviene en materia de expresión; el territorio, como creación artística, se caracteriza por el tránsito dinámico entre la desterritorialización y la reterritorialización, lo cual es característico en la geo-estética. En últimas, "no hace falta nada más para hacer arte: una casa, unas posturas, unos colores y unos cantos, a condición de que todo se abra y se yerga hacia un vector loco como el mango de una escoba de bruja, una línea de universo o de desterritorialización" (Deleuze y Guattari, 1993, p. 187). El territorio, dado que no preexiste, es, pues, condición necesaria para la emergencia del arte. Es tarea de la geo-estética determinar las relaciones entre territorio y la producción artística misma (entendiendo que la producción del territorio es concebida en símisma como arte).

Ahora bien, resulta importante señalar que el paralelo entre obra y territorio es insuficiente; la analogía según la cual la obra de arte es al hombre como el territorio, al animal no se basta a sí misma, ya que no comprende la complejidad de las operaciones descritas a lo largo de este escrito. Lo que es de destacar es que el elemento territorializante se erige como un factor estético, que está presente no solo en el hombre, sino en el animal y en la naturaleza misma. Ese factor territorializante deleuziano es condición de posibilidad de la obra y del territorio. Dado que el arte lo concibe Deleuze desde el animal que demarca un territorio, el factor territorializante, en tanto factor estético, tiene su origen o génesis en la emergencia del territorio, que es la misma emergencia del arte, por lo que es factible afirmar una suerte de simbiosis entre ambos conceptos. Como se mencionó en la introducción, el concepto de geo-filosofía lleva a la pregunta por las distintas relaciones que se establecen en torno al medio geográfico, entre ellas, claro está, la relación estética. Con la introducción de ese concepto, Deleuze y Guattari revelan un punto de inflexión: el quiebre con la tradición que se centraba en la historia, para pasar ahora a enfocarse en la geografía; en consecuencia, lo que hay es una manifestación de la importancia del espacio, puro giro espacial. 
A diferencia de los apartados anteriores, en los que los ejemplos se antojaban innecesarios, la intervención del hombre en el espacio físico sí amerita ejemplos que manifiesten la territorialización como creación artística, pues la intervención es concreta y puede ser delimitada. De igual forma, en la territorialización el pliegue se torna más evidente, pues resuelve la tensión entre el caos colindante y el territorio propio, diferenciación diferenciante entre medios, escisión armónica entre el caos y el encasa. Ya se dijo que Deleuze deja entrever la posibilidad de la geo-estética con el concepto de territorio y el de geo-filosofía. Una vez se entiende que el arte trasciende las fronteras de la carne, que comienza con el territorio, es factible concebir la geoestética, en virtud del giro espacial. El denominado land art es un buen ejemplo de vanguardia que viene a respaldar lo aquí sostenido, pues en él se ponen de presente las intervenciones sobre el espacio, la elaboración de pliegues, la importancia del giro espacial y su influencia en la estética; ya que el arte es posible como geografía, como intervención física en el mundo cósmico, se entiende y se visibiliza la Tierra como presupuesto o condición necesaria para la creación artística, para la territorialización. "El land art convirtió el objeto escultórico en una construcción del territorio por medio de una expansión hacia el paisaje y la arquitectura" (Careri, 2002, p. 26). Las intervenciones del hombre en el espacio tienen, entonces, una potencia artística en la geo-estética.

Deleuze habla del continuo volver sobre los pasos en la marcación del territorio, del ritornelo; por lo que resulta pertinente el ejemplo de caminar como creación artística. La práctica de caminar tiene una lectura estética y es cada vez más recurrente en el arte.

Antes de levantar el menhir -llamado en egipcio benben, la primera piedra que surgió del caos-, el hombre poseía una manera simbólica con la cual transformar el paisaje. Esta manera era elandar, una acción fatigosamente aprendida durante los primeros meses de vida, que se convertiría más tarde en un acto que dejaba de ser consciente y pasaba a ser natural, automático. A través del andar el hombre empezó a construir el paisaje natural que lo rodeaba (Careri, p. 19).

Para evidenciar el andar como práctica estética podrían citarse varias obras del artista belga Francis Alÿs que vendrían a respaldar lo dicho en este escrito. La escogencia de Alÿs no es caprichosa, pues es un artista cuya creación artística no surge en un taller, sino que precisa salir a la calle a territorializar (el territorio surge por necesidad de aislarse del caos, no preexiste). Su taller es, pues, el paisaje, el medio amorfo en el que crea un en-casa, en el que firma su obra. Otro rasgo 
importante en las obras de Alÿs, y que no es para nada un dato menor ni despreciable, es que sus obras muchas veces están inacabadas o, mejor, el artista vuelve continuamente sobre sus obras, las retoma y las modifica, en un puro ejercicio dinámico y circular, al igual que en el ritornelo (territorialización-desterritorializaciónreterritorialización). En la obra artística de Alÿs está latente la posibilidad de volver sobre sí mismo, de retornar sobre sus propios pasos y que, con todo, la experiencia sea distinta, unicidad que deviene en multiplicidad en la creación de perceptos, que solo puede ser experimentada en el plano de inmanencia de las emociones. En Alÿs, al igual que en Deleuze, lo importante es ante todo el proceso de creación, por encima de la obra en concreto. Se constata así un continuo cambio de la obra, un dinamismo, pues como el ritornelo, la obra no es pétrea ni estática, sino dinámica.

Otra característica recurrente en el trabajo de Alÿs es la acción de caminar. El viaje, el camino, los pasos, las huellas, los trazos, fungen como punto de partida en la creación artística; la acción de caminar deviene en la creación del territorio que, con Deleuze, es el punto de emergencia del arte, trazando distintas fronteras. Por ejemplo, en su obra de 1995, titulada The Leak, Alÿs transita por las calles de la ciudad de Sao Paulo, en Brasil, cargando en sus manos un tarro de pintura que tiene un agujero por el cual esta se cuela, y a medida que el artista va caminando va dejando tras de sí un rastro de pintura de color, va territorializando, deja una huella, a la vez que confecciona pliegues. Con su obra Cuando la fe mueve montañas, la intervención realizada en el paisaje, así como la modificación del medio amorfo y la elaboración de pliegues que se insertan en la Tierra, en el paisaje natural intervenido por la acción humana, se tornan todavía más claros y evidentes; en esta obra, Alÿs se apoya en un número considerable de voluntarios, con los que consiguió trasladar algunos centímetros una duna en Lima, Perú; el trabajo de varias personas y distintas herramientas desembocó en la modificación del paisaje, en la intervención sobre la Tierra misma, dejando claro que la Tierra es un presupuesto para la elaboración del territorio, para la creación de la obra de arte territorializante. La intervención física en elespacio, geografía, deviene estética, geo-estética. Alÿs se manifiesta como un caminante, el artista que territorializa con su caminar, sus pasos son sus huellas, su firma.

Antes resultaba común el ejercicio de naturalizar el paisaje, ahora no resultan extrañas las posiciones que asumen una actitud crítica al respecto. "En Deleuze, el arte es geo-grafía, transformación territorial y expresiva" (Sauvagnargues, p. 147). Ningún territorio preexiste, no es espacio ya dado, "es el ritornelo el que arranca una territorialidad al medio amorfo constituido por movimientos de territorialización y 
desterritorialización" (Sauvagnargues, p. 149). El arte, territorializante, se expresa como esa continua transformación del territorio producto de las perennes entradas y salidas, idas y venidas, de la formación del ritornelo, constituido por el hábito, como ejercicio dinámico de retorno sobre la misma experiencia. El ritornelo, como estar volviendo, es la creación artística misma, y es en el tránsito entre medios que se da la creación de un territorio.

Una vez las condiciones de posibilidad permiten concebir el arte como un ejercicio territorializante, la empresa de la geo-estética encuentra camino por el cual transitar. La creación de un territorio, como morada en medio del caos y entendida como arte, invita a pensar el arte como geo-grafía, y en ese arte el pliegue resalta como elemento protagonista de esa estética. La naturaleza misma está llena de pliegues, pliegue sobre pliegue, pliegue que va al infinito. Las vetas de la naturaleza devienen en pliegues que caracterizan el arte de la naturaleza. El hombre y el animal también terminan por construir pliegues en la edificación de su morada. El pliegue siempre se encuentra entre dos cosas, es diferenciación diferenciante, el pliegue va a entrar a realizar la distinción entre el en-casa y el caos circundante, como correlato. Al igual que en el barroco, en la naturaleza los pliegues se curvan y recurvan de manera tal que son llevados hasta el infinito. Con el barroco, Deleuze hablaba de una tensión que se resuelve a través de la distinción entre dos pisos, de manera que se alcance la armonía que refiere Leibniz por las correspondencias entre los pisos, ya que se “distribuye la escisión”. La articulación de esos dos pisos sustituye la distinción entre dos mundos. El primer piso se refiere a la fachada, a lo físico, lo puramente corporal, mientras el interior se identifica con el piso de arriba, se refiere a lo metafísico, a las almas. De manera similar, en términos de la geo-estética, el pliegue distribuye la escisión entre el caos y el territorio propio, de modo que resuelve la tensión existente y permite la creación de un territorio para aislarse del caos como una expresión del ejercicio de creación artística, puro ritornelo.

Deleuze y Guattari catalogan el arte entre las operaciones de la vida, desacralizando la creación artística y percatándose de la potencia creadora en la naturaleza misma, y no exclusivamente en la actividad del hombre. El punto recae en la concepción del arte como ejercicio territorializante, como creación de un territorio propio que permite un aislamiento del entorno caótico, que da entrada al ritornelo como agenciamiento de ese territorio y en el que se denota la operación consistente en encontrar pliegues en todo lado, es decir, en encontrar aquello que es recurrente en el sistema. El espacio cósmico deviene en territorio, que solo puede ser experimentado en el plano de inmanencia preciso de las expresiones; es el territorio el que hace 
existencialmente posible la geo-estética. En la construcción del territorio se efectúan pliegues; nuevamente, la operación consiste en encontrar la recurrente elaboración de pliegues en el sistema. Tenemos, entonces, un pliegue como mundo cósmico, el ojo de dios leibniziano, pliegue y topología (en el que es la tierra misma la que viene a ser descrita); pero también tenemos un pliegue resultante de la intervención en el paisaje (el territorio se introduce en la Tierra para producir la forma que precisa, hace uso de las vetas de la naturaleza si se quiere), pliegue que es consecuencia de la elaboración del en-casa, de la morada que aísla el caos, diferenciación diferenciante entre exterior caótico e interior como territorio propio y que deviene visible gracias a las condiciones de visibilidad e inteligibilidad.

Así las cosas, podríamos sospechar que existe un arte barroco sin la jerarquía que se desprende de la filosofía de Leibniz, entendido como aquel modelo de contraste entre la oscuridad y la luz, forma y fondo, arriba y abajo. El pliegue en la geoestética mantiene el rasgo de la continua elaboración o confección de pliegues, y en cada pliegue la distribución variada de fuerzas es distinta, la variación se erige como principio.

\section{REFERENCIAS}

Boyer, A. (2009). "Archipelia, lugar de relación entre (geo)estética y poética”. Nómadas, Núm. 31, pp. 13-25.

Careri, F. (2002). El andar como práctica estética. Barcelona: Gustavo Gili, SL.

Deleuze, G. (1989). El Pliegue. Leibniz y el barroco. Barcelona: Paidós.

Deleuze, G. y Guattari, F. (1993). ¿Qué es la filosofía? Barcelona: Anagrama.

Deleuze, G. y Guattari, F. (1994). Mil mesetas. Capitalismo y esquizofrenia. Valencia: Pretextos.

Leibniz, G. W. (1974). Monadología. Madrid: Universidad Complutense.

Rancière, J. (2000). Le partage du sensible. Esthétique et politique. París: La Farique Éditions.

Wölfflin, H. Renacimiento y Barroco. Barcelona: Paidós Estética.

Sauvagnargues, A. (2006). Deleuze. Del animal al arte. Buenos Aires: Amorrortu. 